Journal of Animal and Veterinary Advances 10 (9): 1124-1126, 2011

ISSN: $1680-5593$

(C) Medwell Journals, 2011

\title{
Effects of Sildenafil on Dental Tissue
}

${ }^{1}$ Ferhan Yaman, ${ }^{2}$ Sevda Soker, ${ }^{1}$ Serhat Atilgan, ${ }^{1}$ Behcet Erol, ${ }^{5}$ Harun Alp,

${ }^{1}$ Serkan Kamil Agacayak, ${ }^{3}$ Ahmet Gunay, ${ }^{4}$ Bayram Ince and ${ }^{4}$ Mehmet Dalli

${ }^{1}$ Department of Oral and Maxillofacial Surgery, Faculty of Dentistry,

University of Dicle, 21280 Diyarbakir, Turkey

${ }^{2}$ Department of Histology and Embryology, Faculty of Medicine,

University of Dicle, 21280 Diyarbakir, Turkey

${ }^{3}$ Department of Periodontology, Faculty of Dentistry, University of Dicle, 21280 Diyarbakir, Turkey

${ }^{4}$ Department of Operative Dentistry and Endodontics, Faculty of Dentistry,

University of Dicle, 21280 Diyarbakir, Turkey

${ }^{5}$ Department of Pharmacology, Faculty of Veterinary, Dicle University, 21280 Diyarbakir, Turkey

\begin{abstract}
To investigate the effects of Sildenafil on dental tissue. The study was performed with adult female Wistar-Albino rats. Control group $(n=7)$ were fed on standard laboratory diet until surgery. The study group $(\mathrm{n}=7)$ were administered Sildenafil orally with orogastric tube $10 \mathrm{mg} \mathrm{kg}^{-1}$ once a day for 30 days. Each rat was anesthetized and mandibular bone with incisor teeth and soft tissue were removed. Dental pulp, dentin, periodental ligament, periodental soft tissue and bone were examined histologically. Neovascularization on the dental pulp and gingiva were significantly higher in the study group. Sildenafil can be used as a supporting factor in dental tissue healing.
\end{abstract}

Key words: Sildenafil, dental tissue, experimental research, dental pulp, tissue, bone

\section{INTRODUCTION}

Sildenafil, being a PDE-5 inhibitor is a strong peripheral vasodilator (Kothari and Duggal, 2002; Qian et al., 2005). PDE-5 inhibitors which are used in erectile dysfunction treatment are currently used to a great extent in cardiovascular and neurosurgery and in clinics for the treatment of patients with diseases of the brain vessels and microcirculation failure. In recent years, the use has been observed in plastic surgery clinics after flap surgery with the aim of increasing graft circulation (Derici et al., 2009).

The effect is seen as leading to vasodilation by increasing cyclic Guanosine Monophosphate (cGMP) by means of Nitric Oxide (NO) (Langtry and Markham, 1999; Robson et al., 2004; Salcido, 2008; Sarifakioglu et al., 2004). The effect on bone healing is an interesting current topic and there are studies showing benefits in the treatment of fractures (Akgul and Alemdaroglu, 2008).

\section{MATERIALS AND METHODS}

In literature, the reported dose of sildenafil to be administered varies from $3-20 \mathrm{mg} \mathrm{kg}^{-1}$ per day in animal models. A dose of $10 \mathrm{mg} \mathrm{kg}^{-1}$ sildenafil achieves possible systemic protective effects in rats. Higher doses (over $20 \mathrm{mg} \mathrm{kg}^{-1}$ ) may have greater vasodilatatory effects but they may also have side effects such as hypotension, diminished tissue perfusion and excessive antiinflammatory response whereas doses $<10 \mathrm{mg} \mathrm{kg}^{-1}$ are less or not effective at all (Irkorucu et al., 2008, 2009). For this reason, we chose to administer sildenafil as a single daily dose of $10 \mathrm{mg} \mathrm{kg}^{-1}$.

Rat incisor teeth were placed in 10\% formaldehyde solution for 2 weeks then fixed in Bouin's solution for 2 days. The fixed bone samples were decalcified in a $10 \%$ acetic acid, $0.85 \% \mathrm{NaCl}$ and $10 \%$ formalin solution. Paraffin blocks were then prepared in a standard manner. The 4 sections were taken 6-7 microns in thickness at 20 micron intervals from the paraffin blocks. These sections were stained with haematoxylin eosine and evaluated separately.

\section{RESULTS AND DISCUSSION}

Histological results obtained from the sections. The increase in capillaries was evaluated according to the histological recovery scale shown in the Table 1 and 2 .

Corresponding Author: Ferhan Yaman, Department of Oral and Maxillofacial Surgery, Faculty of Dentistry, University of Dicle, 21280 Diyarbakir, Turkey 
Table 1: Histologic examination results of the incisor teeth pulp of the control group rats

\begin{tabular}{lcccc}
\hline \multicolumn{5}{c}{ control group rats } \\
Rat No. & $\begin{array}{c}\text { 1st } \\
\text { section }\end{array}$ & $\begin{array}{c}\text { 2nd } \\
\text { section }\end{array}$ & $\begin{array}{c}\text { 3rd } \\
\text { section }\end{array}$ & $\begin{array}{c}\text { 4th } \\
\text { section }\end{array}$ \\
\hline 1 & 0 & 0 & 0 & 0 \\
2 & + & 0 & + & 0 \\
3 & 0 & 0 & 0 & 0 \\
4 & 0 & + & 0 & 0 \\
5 & 0 & 0 & + & 0 \\
6 & 0 & + & 0 & 0 \\
7 & + & 0 & 0 & + \\
\hline
\end{tabular}

Increase in hyperemia and number of capillaries Absent: 0 , Present: +

Table 2: Histologic examination results of the incisor teeth pulp of the Sildenafil group rats

\begin{tabular}{lcccc}
\hline & 1st & 2nd & 3rd & 4th \\
Rat No. & section & section & section & section \\
\hline 1 & + & + & + & 0 \\
2 & + & + & + & + \\
3 & + & + & + & + \\
4 & + & + & + & 0 \\
5 & + & + & + & + \\
6 & + & + & + & + \\
7 & 0 & + & + & + \\
\hline
\end{tabular}

Increase in hyperemia and number of capillaries. Absent: 0 , Present: +

Statistical analysis: SPSS 15.0 for Windows was used. The Mann-Whitney U-test was used for the two independent groups of control group and Sildenafil group. A highly significant difference was found between the two groups $(\mathrm{p}<0.001)$.

In the study group results while the dentine tubular structure and odontoblast arrangement in the neighbouring pulp was normal, an increase was observed in the vascular structure in the pulp canal and additionally a partial loss of fibres and cells in the connective tissue area. Epithelium thickening of the gingiva epithelia free section was seen whereas the periodental membrane area was observed to be normal. In addition to $\mathrm{HE}$ (Haematoxylin Eosine) staining of structures, Masson staining results showed an increase and dilatation of vascular structures in the pulp canal. In comparison to the control group, the vascular structure canals in the peridontal membrane were observed to be more dilated and the gingiva vascular structures were observed to have increased.

No change was determined in the structure of the alveolar bone (Fig. 1a and 2a). In the images of the control group no change was determined in the dental structures. The dentinal tubules, odontoblast extensions and pulp canal width and structure were seen as normal. No change was observed in the structure of the alveolar bone canal and surrounding periodontium.

The gingiva epithelial structure was observed to be normal (Fig. 1b and 2b). In this experimental research to investigate the use of Sildenafil in dentistry, the histological results from the sections showed an increase in vascularisation, particularly in the pulp canal in the group which had been given Sildenafil.

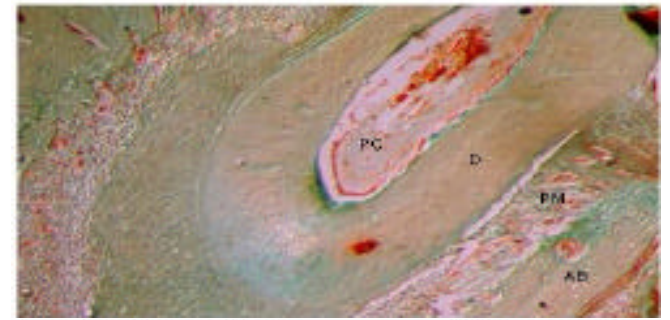

(b)

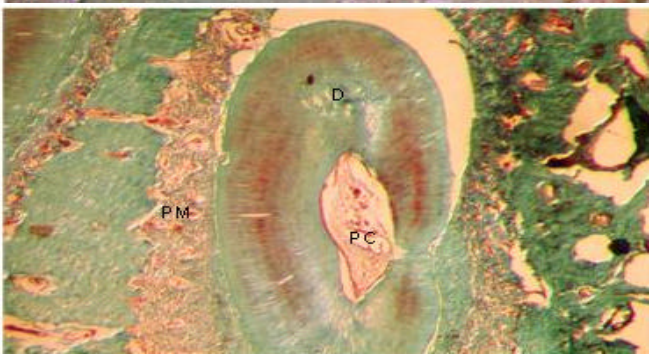

Fig. 1: a) Stereomicroscope image of dental tissue of the study group. Masson staining ( $\mathrm{AB}$ : Alveolar Bone, PM: Peridontal Membrane, PC: Pulp Canal, D: Dentine); b) Stereomicroscope image of dental tissue of the control group. Masson staining (D: Dentine, PC: Pulp Canal, PM: Peridontal Membrane)

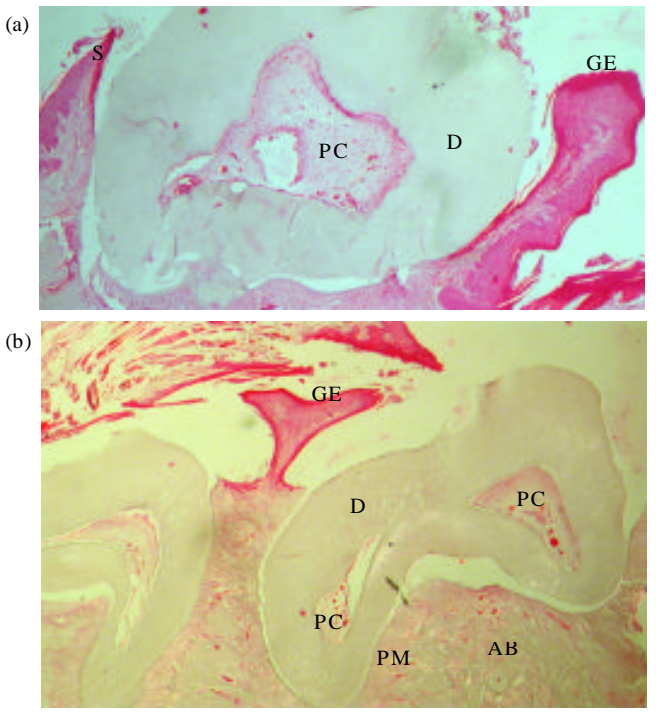

Fig. 2: a) Stereomicroscope image of dental tissue of the study group. Haematoxylin eosine staining (GE: Gingiva Epithelia, S: Sulcus, PC: Pulp Canal, D: Dentine); b) Stereomicroscope image of dental tissue of the control group. Haematoxylin eosine staining (AB: Alveolar Bone, GE: Gingiva Epithelia, PM: Peridontal Membrane, PC: Pulp Canal, D: Dentine) 
Applied systemically or locally, this may be beneficial to the healing and keeping the tooth alive in pulp capping in situations where the pulp blood flow has been impaired by dental trauma or for other reasons. There is a need for the evaluation of further clinical research of the use of local or regional injections, systemic applications or cements. The application of Sildenafil was seen to lead to an increase in vascularisation in the gingiva and pulp without creating any change to the alveolar bone.

\section{CONCLUSION}

In the study, the findings of this study show that Sildenafil can be used as a supporting factor in dental pulp and gingiva healing. Further clinical studies (The effect of Sildenafil on conditions such as gingival flap surgery, gingiva injury, exposed dental pulp or dental trauma) are needed to clarify the usefulness of Sildenafil for gingiva and dental pulp healing.

\section{REFERENCES}

Akgul, T. and B. Alemdaroglu, 2008. Phosphodiesterase 5 inhibitors may facilitate bone fracture recovery. Med. Hypotheses, 70: 461-462.

Derici, H., E. Kamer, H.R. Unalp, G. Diniz and A.D. Bozdag et al., 2009. Effect of sildenafil on wound healing: An experimental study. Langenbecks Arch. Surg., 395: 713-718.
Irkorucu, O., B.H. Ucan, G.K. Cakmak, A.U. Emre and O. Tascilar et al., 2009. Does sildenafil reverse the adverse effects of ischemia on ischemic colon anastomosis: Yes, no. Int. J. Surg., 7: 39-43.

Irkorucu, O., O. Tascilar, G.K. Cakmak, K. Karakaya and A.U. Emre et al., 2008. The effect of sildenafil on an animal model for ischemic colitis. Digestive Dis. Sci., 53: 1618-1623.

Kothari, S.S. and B. Duggal, 2002. Chronic oral sildenafil therapy in severe pulmonary artery hypertension. Indian Heart J., 54: 404-492.

Langtry, H.D. and A. Markham, 1999. Sildenafil: A review of its use in erectile dysfunction. Drugs, 57: 967-989.

Qian, C.N., M. Takahashi, R.J. Kahnoski and B.T. Teh, 2005. Effect of sildenafil citrate on an orthotopic prostate cancer growth and metastasis model. J. Urol., 170: 994-997.

Robson, M.C., D.A. Dubay, X. Wang and M.G. Franz, 2004. Effect of cytokine growth factors on the prevention of acute wound failure. Wound Repair Regener., 12: 38-43.

Salcido, R.S., 2008. Viagra and wound healing: The NO connection. Adv. Skin Wound Care, 21: 106-109.

Sarifakioglu, N., S. Gokrem, L. Ates, U.B. Akbuga and G. Aslan, 2004. The influence of sildenafil on random skin flap survival in rats: An experimental study. Br. J. Plastic Surg, 57: 769-772. 